\title{
MEMÓRIA INVOLUNTÁRIA, OS SENTIDOS DISPERSOS DO DESEJO: RITMOS E COLORAÇÕES EM FREUD E EM PROUST
}

\author{
Maria Barcelos de Carvalho Coelho*
}

RESUMO:

\begin{abstract}
Por este texto procurou-se demonstrar a possibilidade de uma leitura através da qual se pode perceber a estética autoral de Freud, nos primeiros anos da descoberta dos processos inconscientes. As conexões com o texto de Proust permitiram comparar o estilo da narrativa dos dois autores. O estilo, em seus fraccionamentos sintáticos, espelharia as transformações culturais e tecnológicas do ritmo fin du siècle.
\end{abstract}

PALAVRAS-CHAVE: inconsciente, desejo, corpo, signo, memória.

A obra de Deleuze, Proust e os signos (1987), trazendo o desvelamento dos princípios de uma lógica que se esclarece pela classificação dos signos, signos mundanos, signos amorosos, signos sensiveis e signos artísticos, constrói os traçados de uma "cosmologia" afetiva do universo proustiano, que se daria no percurso da escrita de Em busca do tempo perdido (Deleuze, 1987: 1-25). Expressando também a transterritorialização entre filosofia e literatura, Deleuze decodifica e sistematiza os arquétipos de uma semiologia literária que se inscreve em linhas de tempo; o que o que entraria em cena neste agenciamento literário/filosófico seria o aprendizado do narrador em sua interação subjetiva com os personagens, o tempo e a memória (Deleuze, 1987: 26-38).

Os conceitos deleuzianos que se constroem através da incursão do filósofo pela ciência literária possibilitam mapear signos que também se entrecruzam com a psicanálise. Nesse sentido, considerando a pesquisa de Freud, entre os anos de 18971904, exatamente sua tentativa de compreensão da subjetividade e da dinâmica de seus

|* Mestre em Letras: Estudos Literários (Área de concentração: Teoria da Literatura), 2001. 


\section{EMTESE}

Belo Horizonte, v. 6, p. I-253, ago. 2003

próprios afetos e os afetos de seus "personagens clínicos", a conexão com a filosofia de Deleuze faz sentido quando se observa que a moderna hermenêutica fundada por Freud, é literariamente transcodificada na escritura. A extensa rede textual de Freud tem revelado alguns "sentidos dispersos" do pensamento psicanalítico, o que aproxima as relações entre esses sentidos, e a experiência de autores cujos trajetos se deram no mundo ocidental no fim do século XIX e início do século XX, momento em que o inconsciente ia sendo descoberto e revelado através da escrita "híbrida" do primeiro analista (Coelho, 2001: 21-46). A filosofia de Deleuze, pensada em ressonância com os signos proustianos, possibilita ao filósofo francês traçar a cartografia de uma semiótica sobre o aprendizado do narrador, em cujo trajeto se cruzam ciência e arte (Deleuze, 1987: 48). Ao elevar a experiência do escritor a uma dimensão cujo alcance conteria em si próprio a gênese de um princípio científico, Deleuze abriria caminhos para inscrever a psicanálise nos veios de uma estética filosófica germinada no registro sensivel da linguagem literária.

Tomando, então, como referência a lógica dos signos em Deleuze, diríamos que Freud e Proust poderiam ser percebidos como narradores/tradutores de uma memória que involuntariamente espelha o desejo do autor, entrelaçado aos afetos e dramas de seus personagens. Ao trançarem a malha sinuosa de seus textos, tanto 0 autor de $A$ interpretação dos sonhos, como o de Em busca do tempo perdido, trariam à cena literária os signos de um tempo onde fulguram imagens de uma realidade pulsante, transfigurada, e que se mostra anunciada pela sintaxe desencaixada do texto. Esta forma de escrever que suscita imagens em movimento acelerado, cujos ruídos se mostram nas costuras e nos inacabamentos do texto, Deleuze vai perceber como não estilo, por onde se pode ler a subjetividade fragmentada do autor, em sua interação com o mundo que ele passa a habitar (Deleuze, 1987: 146, 165). 0 narrador, na modernidade contemporânea, apresenta uma performance na qual se pode sentir, pelas palavras, os rumores que prenunciam um novo tempo. Deleuze irá comparar o narrador a uma aranha que, ao tecer sua teia, responde cegamente aos signos de seu desejo - corpo sem órgãos (Deleuze, 1987: 182-183). 0 escritor, envolvido na pulsação do ritmo do desenvolvimento técnico estampa sua voz na malha estriada de seu corpo/texto. Salta e faz vibrar o fio da trama. Envolve-se no ritmo e nas nuanças de uma cultura que se transforma e se mostra pelo philum maquínico das "cordas" da escrita (Deleuze e Guattari, 1997: 115-160). 
Em alguns textos de Freud (1897-1904) é possível perceber esse mesmo tecido rítmico que se enreda pelas imagens produzidas na narrativa. Os sonhos de Freud, segundo ele mesmo, seriam manifestação do desejo, linguagem onde se podem acompanhar os percursos subjetivos e às vezes atormentados do cientista. Sentimos a singularidade da escrita freudiana de modo significativo em sua vasta correspondência, ou em fragmentos de textos que se encontram, muitas vezes, fora do enquadre teórico analítico. Mesmo em alguns relatórios médicos, o escritor se enuncia. As narrativas que vão se construindo ao longo de seus estudos sobre a histeria trazem à superfície da escrita o traço colorante dessa tendência literária do cientista, quando o então jovem neurologista de Viena escreve sobre sua experiência e se expressa sob os signos sensíveis que vêm a tona, pelas fendas involuntárias da memória.

\section{SIGNOS SENSÍVEIS: LITERATURA E MEDICINA}

Deleuze, ao cartografar a semiologia da memória em relação ao tempo, não remete o pensamento a uma imagem fixa em uma estrutura histórica espacial. Traz, sim, um sentido de fluidez afetiva, desdobrada nas palavras, na subjetividade singular dos personagens, nas paisagens. Seriam estes os signos sensiveis que viriam enrolados em territórios percorridos pela escritura; entrelaçamento virtual entre a letra-arte e a vivência concreta do autor no trajeto de sua obra. A memória, para Deleuze, se envolve e se dissolve na corrente do tempo, nos caminhos da experiência do escritor. Para o autor de Proust e os signos, o narrador Proust teceria infinitas imagens de tempo: tempo do amor, tempo da ilusão, tempo da desilusão, da morte e da vida, sempre à procura de uma verdade, no seio desse tempo perdido ou redescoberto que põe em ação os afetos, signos da memória, memória dos sentidos. Algumas vezes a memória se cristaliza na corporalidade do escritor: a visão, a audição, o paladar, o olfato. Vozes do corpo, sensações.

Os signos sensíveis se enlaçam na escrita. Esses podem ser observados, dentre inúmeras fulgurações do tempo, na conhecida reminiscência de Proust, em sua 


\section{EMTESE}

Belo Horizonte, v. 6, p. I-253, ago. 2003

experiência com a madeleine. 0 narrador se recorda, quando criança, do paladar de um biscoito de fabricação caseira, saboreado em casa de sua tia Eulalie. 0 gosto do biscoito traz o sentido do "sabor" de Combray, cidade onde o narrador teria passado a infância. 0 ritornelo proustiano lampeja no pensamento a "essência" de sua cidade natal: os signos sensiveis envolvem a lembrança com as qualidades de cor e temperatura das paisagens do campo. A escrita registra a chama da vida, desejo impresso na corrente pulsional das palavras (Coelho, 2001: 68-77)

Em Crítica e Clínica (1996), último trabalho de Deleuze, o tema do processo da escrita retornará a seus agenciamentos críticos. 0 filósofo irá se ocupar naquele momento de sua obra, curiosamente, o tempo que antecede sua própria morte, da dialética entre a vida e a literatura. Expõe em seu último livro a possibilidade de compreensão do potencial clínico que teria a arte do escritor em seu trajeto pela obra: ao percorrer o "corpo" do texto em suas viagens interiores, o escritor viria a ser médico, médico de si mesmo e do mundo (Deleuze, 1996: 13-14).

Deleuze perceberia uma natureza terapêutica na literatura: essência imanente à escritura; colorido e música, dialética dinâmica criada entre o narrador e os personagens. Essa potência clínica singular, que teria o artesão da letra registra-se, para o filósofo, no tramado da invenção de uma língua que o filósofo vê como território crítico: língua estrangeira que se eleva acima das palavras. No entanto, em Proust, não obstante a crítica sociológica que envolve narrador e personagens na dinâmica dos devires que espelha a aristocracia decadente do final do século XIX na Europa ocidental, o sentido de pintura, música e sabor parecem transpor esse linguajar gaguejante do escritor para se territorializar nas palavras e inundar o texto de nuanças colorantes e sonoras. Puro afeto que percorre não só a semântica mas também a sintaxe do tramado escritural. Fenômeno sinestésico, epifânico, que se percebe, ainda no primeiro volume da obra de Proust, No caminho de Swann. Neste livro o autor traz ao leitor sensações produzidas por cores indefinidas, que muitas vezes se enlaçam aos sabores, ao ritmo e às cores que a leitura leva a sentir.

Descrevem-se aqui os sentidos de uma memória colorante e "degustativa" - azul indefinido, onde cor e sabor se mesclam em um só signo. 
Dentre os quartos cuja imagem eu mais seguidamente evocava em minhas noites de insônia, nenhuma se parecia menos com os quartos de Combray, polvilhadas de uma atmosfera granulosa, polinizada, comestivel e devota do que a do Grande Hotel de Balbec, cujas paredes esmaltadas continham como as de uma piscina onde a água azuleja, um ar puro e salino. (Proust, 1995: 369)

A atmosfera desta descrição seria produzida pela impressão inconsciente de imagens sensoriais, criando neste caso um pensamento estético prazeroso. 0 acolhimento receptivo por parte do leitor, permite, por outro lado, a possibilidade de ampliação do campo semântico imaginativo da pessoa que lê, efeito curativo da escrita, desencadeamento de imagens, associações, possibilidade de vida e criação. Quando o escritor ultrapassa seu próprio processo delirante, nos devires que 0 assomam, a literatura, para Deleuze, torna-se "um empreendimento de saúde" (Deleuze, 1996: 9).

A escrita de Freud do período Fliess, época em que o médico vienense mergulha em sua própria realidade psíquica, mostra-se percorrida pelos ritmos, fluxos e colorações de matérias de expressões encontrada fartamente na obra de Proust. Em algumas passagens de cartas endereçadas a Fliess, Freud torna-se um narrador meticuloso, expressando um estilo semelhante ao do autor de Em busca do tempo perdido. As cartas mostram a fadiga, as decepções, o ritmo delirante da escrita e da clínica. No entanto, em alguns momentos, a sensibilidade dos signos se mostra em pequenos intervalos, clareiras, onde o missivista deixa-se penetrar pela natureza. Sol, montanhas e mar recompõem o corpo freqüentemente adoecido.

As reminiscências descritas nas cartas mostram o desejo do analista em deslocar-se, sair de seu lugar, empreender viagens. Freud percorre caminhos interiores e exteriores e expressa, no texto, os signos sensíveis de seu desejo. Em Proust esse jorro de palavras colorantes perpassa o texto de ponta a ponta. Ciência e ficção se entrelaçam na inventividade "maquínica" do escritor moderno.

A percepção de uma estilística da fragmentação, tal como é percebida por Deleuze, pode ser observada em Freud, notadamente em Estudos sobre histeria. Quando o analista aos poucos desvela os processos paralizantes inconscientes, de alguma forma retidos na memória de suas pacientes, o autor passa ao texto suas mais profundas impressões. Não é de se estranhar o fato de que nesta época Freud irá perceber, aos poucos, que suas famosas pacientes iriam "sofrer de reminiscência": 


\section{EMTESE}

Belo Horizonte, v. 6, p. I-253, ago. 2003

memória aprisionada pela impossibilidade de expressão nas palavras. Seria então a arte de decifrar os arquétipos simbólicos da linguagem inconsciente que levaria Freud a dar um sentido estético/científico aos mecanismos da realidade psíquica. A descoberta da nova hermenêutica dos afetos (psicanálise), vai aos poucos, permitindo a Freud atravessar a subjetividade do universo feminino. 0 olhar do médico percebe a misteriosa natureza daqueles corpos mudos - belle indifference - cujo sono e movimentos o artista desperta. No declinar do século XIX, tanto Proust como Freud mimetizam em suas obras imagens de um tempo que não mais se representa em cenários estanques, mas sim expressa a velocidade dos signos que se derramam involuntariamente, pelas tonalidades colorantes da arte. Proust associa a plasticidade estética das mulheres fin du siècle à imobilidade estática das árvores do Bois de Boulogne em Paris. Imprime no texto a nostalgia de um mundo cujo ritmo se acelera e se mostra pela escrita onírica do narrador.

\section{NO TOM DA LETRA, O ESTRANHAMENTO DO CIENTISTA}

Em Freud aconteceria então "atravessar" os corpos, diagnosticar as patologias clínicas de sua época. 0 neurologista, aos poucos, penetra a subjetividade das mulheres, e ao fazê-10, o escritor desconstrói também a estrutura de uma práxis médica que situava, de um lado, o saber positivo do anatomista, e do outro, a postura "paciente" do sujeito. A desrazão passaria a falar por si mesma. 0 doente passa a ganhar um novo estatuto clínico, e as histéricas de Freud, com suas paralisias motoras e seu idioleto secreto, arrebatam do tradutor dos sonhos os primeiros signos de uma ciência inaugural: a psicanálise.

Em função da literatura sobre a histeria, Freud sentiria um certo desconforto quando se percebe afetado pelo estranhamento que the causa 0 rumo que tomam suas pesquisas médicas; surpreende-se com a tonalidade literária de seus relatórios clínicos. 
No outono de 1892, ao tratar de sua paciente Elizabeth Von R, Freud escreveria:

Ainda me causa estranheza que os relatos que escrevo pareçam contos e que falta-1hes a marca de seriedade da ciência (...) a verdade é que o diagnóstico local e as reações elétricas não levam a parte alguma no estudo sobre a histeria, ao passo que uma descrição pormenorizada dos processos mentais a que estamos acostumados nas obras de escritores imaginativos, me permite obter uma espécie de compreensão sobre o curso dessa afecção. (Freud, 1982: 172)

A percepção de uma estética literária moderna, posta no estilo do narrador, se expressaria, no caso de Freud, por um certo involuntarismo de seus desejos: signos sensíveis de uma memória flutuante. Sua linguagem se constrói, em grande parte, na fronteira (interface) entre o discurso científico e o discurso filosófico literário. Freud, em sua dualidade inventiva, jamais deixará de recorrer à literatura, tanto para escrever como para se inspirar na criação de sua obra: de um lado, o iluminismo científico, onde o primeiro analista tenta buscar a lógica racionalista obtida em sua experiência clínica; do outro o escritor que mergulha em suas próprias sensações - imagens (acontecimentos e encontros), viagens (a dor, 0 corpo adoecido e a morte que encarna seus fantasmas), o romance familiar (o nascimento dos filhos, o amor). Seu olhar retém a poesia do cotidiano, e é desse campo experimental sensível que o "doctor poeta" capta a matéria básica pulsional de seu texto. Puro desejo, onde ciência e poesia cruzam o itinerário de Freud à procura do território inconsciente.

Entrelaçando o afeto que sente por seus pacientes, ao curar a histeria de Elizabeth, em 1894, o jovem médico participa como ator e personagem na cena montada, que dá um gran finale ao seu teatro clínico. Retirando-se da história e da trama científica, sua escrita vai ficando ainda mais próxima a uma linguagem ficcional, à medida que o terapeuta se coloca entre o narrador/médico e o drama de sua paciente.

Na primavera de 1894, eu soube que ela iria a um baile particular para o qual eu poderia obter um convite; e não deixei escapar a oportunidade de ver minha ex-paciente passar por mim numa dança animada. Depois dessa ocasião, casou-se com alguém que não conheço. (Freud, 1982: 172) 


\section{EM TESE}

Belo Horizonte, v. 6, p. I-253, ago. 2003

0 texto, no decorrer da escrita, se daria, segundo Roland Barthes, num "amalgamar-se de códigos." A escrita híbrida do cientista é também expressa por uma construção genérica onde se percebem elementos narrativos de contos ou romances. Segundo Barthes, a escrita viria exatamente do permitir-se entrar "nos desvios e ruídos da linguagem", aquilo que o lingüista francês, citando Lautréamont, chama "a modéstia do escritor":

só a escritura pode quebrar a imagem teológica imposta pela ciência, recusar o terror paterno espalhado pela "verdade" abusiva dos conteúdos e dos raciocínios, abrir para a pesquisa o campo completo da linguagem, com suas observações lógicas, o amalgamar-se de seus códigos, as suas paródias; só a escritura pode opor à segurança do cientista - na medida em que ele exprime sua ciência... a modéstia do escritor. (Barthes, 1988: 97-101)

0 estilo de Freud se enlaça em sua ciência e, assim, contando as histórias singulares de seus pacientes, a arte do médico é revelada. Seus personagens recebem nomes e são diferenciados exatamente pela expressão de seus afetos: Ana 0, Elizabeth, Dora, 0 homem dos lobos, 0 homem dos ratos, Gradiva, Leonardo - pequenos romances de cada tormento psíquico, explicados pelo deslizamento da razão territorializada na arte de narrar e de criar a lógica dos signos. Barthes e Deleuze, ultrapassando os sentidos de um pensamento centralizador e cerebral, mostram as artérias oxigenadas da escrita, quando o autor se permite percorrer pelos devires que the assomam e o fazem experimentar sadiamente o seu próprio processo delirante.

Quando Freud mergulha nas imagens de seus próprios sonhos, a letra registra a vitalidade libidinal de seu inconsciente. A fala poética, expressão dessa libido, se incrusta às descobertas do processo onírico; os signos do artista, em sua extensão literária, refletem a memória inconsciente do analista. Seriam então as sensações, os afetos dispersos no texto, que guiariam o escritor. 0 desejo, com seus recortes musicais e colorantes, violentam o pensamento e ativam a criação. Põe movimentos à invenção maquínica moderna mimetizada na escrita. 0 texto, em sua organicidade deslubrificada, tem que funcionar, tal qual a engrenagem fotográfica, o aeroplano, o cinema e o motor do automóvel que, invisivelmente, acelera o ritmo do homem em seu trânsito errante. 0 texto expressa a fragmentação do mundo e a realidade da interação do sujeito com a vida pode ser apreendida pela arte de 
narrar: estética do estilhaçamento, trajetos, platôs, geografia de uma história tortuosa sendo construída. A arte demanda velocidades que capturem a imagem do tempo no traço gráfico, no gesto, no ritmo da música, enfim nas formas de expressão da memória involuntária que se dissolve na obra, no corpo do texto: espaço onde a trama fabuladora da escrita revela o tempo sendo transformado e redescoberto. A engrenagem da escrita espelha a máquina, motor que funciona, mas que fere o ideal estético de Freud, homem que trabalha na tensão do espaço e do tempo.

Numa carta a Fliess, datada de 21 de setembro de 1899, Freud deixa transparecer, mais uma vez, seu estranhamento em face ao deslocamento sintático de sua própria narrativa:

Em alguma parte dentro de mim há um gosto pela forma, uma apreciação da beleza como uma espécie de perfeição; e as frases tortuosas de meu livro do sonho, ofenderam profundamente meus ideais. (Masson, 1996: 374)

Os deslizamentos estéticos da montagem da obra de Freud mostram, mais uma vez, a experiência angustiante do narrador frente aos caminhos inconscientes que a letra/arte passa a expressar.

Deleuze, em Proust e os signos, irá dizer que o narrador, em seu aprendizado, se relaciona com sua obra, interagindo com ela numa dimensão de transversalidade comunicacional (Deleuze, 1987: 168). Entram, no cenário da escrita, a abstração temporal e corporal do autor no seio de sua experiência. Isto pressupõe que o olhar oblíquo dessa figura fracionada que é o narrador, na modernidade, funciona no texto, como máquina catalisadora dos afetos. Afetos, neste caso entendidos não apenas como os sentidos do corpo, mas as sensações, predisposições psicológicas e sentimentos que se expressam através da subjetividade do homem moderno, estilhaçado pela progressiva rede de informação na qual ele se envereda e passa a habitar. Torna-se o escritor uma persona invisível entre as figuras imaginárias de sua invenção - saber clínico inconsciente, refletido pelo involuntarismo da memória, puro desejo que se mostra pelas estrias indivisíveis da realidade psíquica. 0 narrador, então, põe em movimento a expressividade própria de seu oficio sempre em devir. (Coelho, 2001: 11) Devires que se enrolam aos signos afetivos dos personagens neste trançado simbiótico com seu criador. 0 artista recria o mundo - o amor, 0 ciúme, a loucura, a dor, a velhice, a morte. Espelha as imagens do maelström 


\section{EM TESE}

Belo Horizonte, v. 6, p. I-253, ago. 2003

(Rimbaud, 1995: 207) - vértice abissal de seu desejo, onde o narrador-aranha, vibrando pelos fios de sua teia, procura tecer as malhas do tempo na materialidade da obra. As palavras se colorem nas espirais da memória involuntária, que se escapa às ruînas do mundo.

Pintura e música se imprimem na letra quando o autor finalmente redescobre o tempo e se vê refletido em suas cores: matizes de seus sonhos, consagração final de suas fantasias, corporificação de seus fantasmas.

ABSTRACT :

Using as reference Deleuze's Marcel Proust et les signes (1964/1970) and Critique et clinique (1993) - in which one can detect a possible approach to literature and psychoanalysis through an esthetic philosophy of language, connections between texts by Freud and Proust are established by means of the concepts of "involuntary memory" and "clinic".

KEY WORDS: unconscious, desire, body, sign, memory. 
BENJAMIN, Walter. A imagem de Proust. In: - Magia $e$ técnica. Arte e política. Tradução de Sergio Paulo Rouanet. São Paulo: Ed. Brasiliense, 1985. p. 36-49.

BARTHES, Roland. Das ciências à literatura. Jovens pesquisadores, In: - O rumor do língua Trad. de Leila Perrone Moisés. São Paulo: Ed. Brasiliense, 1988. p. 97-101.

COELho, Maria Barcelos. Freud e a Estética da modernidade. In: - Artelclínica: A revelação do escritor: Uma leitura dos fragmentos da escrita de Sigmund Freud entre os anos (1887-1904). Belo Horizonte: Biblioteca da Faculdade de Letras, UFMG, 2001.

COMPAGNON, Antoine. Os cinco paradoxos da modernidade. Trad. de Cleonice Paes Barreto Mourão, Consuelo F.Santiago e Eunice D. Galéry. Belo Horizonte: Ed. UFMG, 1996.

DELEUZE, Gilles. Proust e os signos. Trad. de Antônio Carlos Piquet e Roberto Machado. Rio de Janeiro: Forense Universitária, 1987.

- Crítica e clinica. Trad. de Peter Pal Pelbar. São Paulo: Ed. 34, 1996.

DELEUZE, Gilles; guatTARI, Félix. Acerca do Ritornelo. In: Mil Platôs. Capitalismo e esquizofrenia. Trad. de Aurélio Guerra Neto. São Paulo: Ed. 34, 1997.

FREUD, Sigmund. Estudos sobre histeria. (1893-1895) Rio de Janeiro. 1982. (Obras psicológicas completas de Sigmund Freud, v. III)

- Primeiras publicações psicanalíticas. Trad. de Margarida Salomão. Rio de Janeiro: Imago, 1982. (Obras psicológicas completas de Sigmund Freud, v. III)

MASSON, Jefrey Moussaieff. A correspondência completa de Sigmund Freud para Wilhelm Fliess. 1887-1904. Trad. de Vera Ribeiro. Rio de Janeiro: Imago, 1986.

PROUST, Marcel. No caminho de Swann. Trad. de Mário Quintana. 18. ed. revista por Maria Lúcia Machado. Rio de Janeiro: Editora Globo, 1995. (Em busca do tempo perdido. VI)

RIMBAUD, Arthur. (1854-1891) "0 barco bêbado" In: Poesia completa/Arthur Rimbaud. Trad., pref. e notas de Ivo Barrosa. Rio de Janeiro: Topbooks, 1995. 